\title{
Alumina-Based Ceramics for Armor Application: Mechanical Characterization and Ballistic Testing
}

\author{
M. V. Silva, ${ }^{1}$ D. Stainer, ${ }^{2}$ H. A. Al-Qureshi, ${ }^{1}$ O. R. K. Montedo, ${ }^{3}$ and D. Hotza ${ }^{1}$ \\ ${ }^{1}$ Núcleo de Pesquisa em Materiais Cerâmicos e Vítreos (CERMAT), Programa de Pós-Graduação em Ciência e Engenharia de Materiais \\ (PGMAT), Universidade Federal de Santa Catarina (UFSC), 88040-900 Florianópolis, SC, Brazil \\ ${ }^{2}$ CMC Tecnologia, Avenida Roberto Galli 1220, 88845-000 Cocal do Sul, SC, Brazil \\ ${ }^{3}$ Programa de Pós-Graduação em Ciência e Engenharia de Materiais (PPGCEM), Laboratório de Cerâmica Técnica (CerTec), \\ Universidade do Extremo Sul Catarinense (UNESC), Avenida Universitária, 1105, 88806-000 Criciúma, SC, Brazil
}

Correspondence should be addressed to O. R. K. Montedo; oscar.rkm@gmail.com

Received 28 October 2013; Accepted 15 December 2013; Published 9 January 2014

Academic Editor: Shaomin Liu

Copyright (C) 2014 M. V. Silva et al. This is an open access article distributed under the Creative Commons Attribution License, which permits unrestricted use, distribution, and reproduction in any medium, provided the original work is properly cited.

\begin{abstract}
The aim of this work is to present results of mechanical characterization and ballistic test of alumina-based armor plates. Three compositions $\left(92,96\right.$, and $\left.99 \mathrm{wt} \% \mathrm{Al}_{2} \mathrm{O}_{3}\right)$ were tested for $10 \mathrm{~mm}$ thick plates processed in an industrial plant. Samples were pressed at $110 \mathrm{MPa}$ and sintered at $1600^{\circ} \mathrm{C}$ for $6 \mathrm{~h}$. Relative density, Vickers hardness, and four-point flexural strength measurements of samples after sintering were performed. Results showed that the strength values ranged from 210 to $300 \mathrm{MPa}$ depending on the porosity, with lower standard deviation for the $92 \mathrm{wt} \% \mathrm{Al}_{2} \mathrm{O}_{3}$ sample. Plates $(120 \mathrm{~mm} \times 120 \mathrm{~mm} \times 12 \mathrm{~mm})$ of this composition were selected for ballistic testing according to AISI 1045, using a metallic plate as backing and witness plates in the case of penetration or deformation. Standard NIJ-0108.01 was followed in regard to the type of projectile to be used $(7.62 \times 51$ AP, Level IV, $4068 \mathrm{~J})$. Five alumina plates were used in the ballistic tests (one shot per plate). None of the five shots penetrated or even deformed the metal sheet, showing that the composition containing $92 \mathrm{wt} \% \mathrm{Al}_{2} \mathrm{O}_{3}$ could be considered to be a potential ballistic ceramic, being able to withstand impacts with more than $4000 \mathrm{~J}$ of kinetic energy.
\end{abstract}

\section{Introduction}

Ceramics have been considered one of the most important materials for lightweight armor applications due to their low density, high compressive strength, and high hardness [1]. Ceramic materials for using as ballistic armor must be sufficiently rigid to fragment the bullet and reduce its speed, transforming it into small fragments that should be stopped by the layer of flexible material that supports the ceramic. Thus, it is necessary that the ceramic material presents high elastic modulus and high hardness [2]. Fracture toughness is also a very important requirement for this application.

The main ceramic materials used commercially in the development of ballistic armors are $\mathrm{Al}_{2} \mathrm{O}_{3}, \mathrm{~B}_{4} \mathrm{C}, \mathrm{SiC}$, and ceramic matrix composites (CMCs) such as $\mathrm{Al}_{2} \mathrm{O}_{3} / \mathrm{ZrO}_{2}$ system. High cost, processing hindrances, and restrictions to predict ballistic performance from the properties of the material are some drawbacks of ceramic armors [3].
Alumina provides the best cost-benefit ratio among advanced ceramics, featuring high modulus of elasticity, high refractoriness, high hardness, and relatively lower cost. However, because of its low fracture toughness and low flexural strength, ballistic performance of alumina is lower when compared to $\mathrm{SiC}$ and $\mathrm{B}_{4} \mathrm{C}$ [4]. The properties of the alumina may be improved, either by introducing zirconia or by the manufacturing CMCs, which increase fracture toughness and flexural strength by introducing tetragonal zirconia particles or ceramic fibers, respectively $[5,6]$.

Thus, ceramic materials are usually a part of a ballistic personal or vehicle protection system. Even in this case, only with a rigorous control of the microstructure assured a reliable ballistic performance can be. For example, a system consisting of a composite of $\mathrm{B}_{4} \mathrm{C}$ and glass fibers or aramid fibers coated with a protective fabric is often used. The replacement of metallic materials by ceramic materials in armored vehicles 
may lead to weight reduction, autonomy increase, and higher level of protection [7].

A ballistic armor system consists of several layers. The first layer is usually formed of ceramic materials whose function is to cushion the initial impact of the projectile. This layer must fracture the tip of the projectile dissipating much of the kinetic energy of the projectile fragment mass and improve the distribution of impact pressure on the second layer. The second layer is also called backing and is formed of ductile materials. Its function is to absorb the kinetic energy of the fragments derived from the residual projectile and ceramics by plastic deformation [8]. The most important requirement of the backing is no fail during the initial stages of the penetration process of the projectile, that is, the backing must withstand compressive stresses transferred to the ceramic after impact. Thus, it would prevent the penetration of the shrapnel containing high kinetic energy and would not deform excessively, as this would jeopardize the lives of persons protected by the armor or the integrity of the equipment. It is important to mention that impacts at high speeds (high kinetic energies) are high complexity phenomena that present limited reproduction, because parameters such as the incidence of the projectile on the armor, for example, are extremely difficult to be adjusted or prevented [9].

The design of an armor using ceramic materials should consider that the fracture is associated with instantaneous loads in ballistic impacts, which are quite different from those associated with static loads. In static load condition, stresses and strains are distributed throughout the body subjected to the impact and all points are involved in the start of fracture. In the instantaneous loads, stresses and strains are very well localized, so that fractures may occur in an isolated part of the body. This kind of change can dramatically affect the mechanical properties of the material due to the high pressures and loading rates. The impact of high kinetic energy projectiles on the ceramic composite armor usually gives rise to a cone of fractures with radial and circumferential cracks [7].

Projectiles fired over alumina targets, whose tips were flattened, presented higher residual speeds after drilling the targets and therefore greater power of penetration in relation to projectiles with sharp geometry. Moreover, a single layer of ceramic material absorbs more energy than several layers with the same overall thickness [10]. In this case, immediately after the impact on the first plate occurs the formation of an axial crack in the interface between the plates, which causes premature fracture of the assembly. During the first stage of the mechanism of penetration, the most important factor is to keep the integrity of the ceramic so that it can erode the greatest possible amount of mass of the projectile, that is, delaying the startup of the fracture of the ceramic material. This factor is decisive for the choice of the ceramic material to be used.

It is not possible to ensure an effective correlation between ballistic performance and a single characteristic or property of the material, due to the dynamic nature of the event occurring at intervals of time ranging from nano- to microseconds. Thus, ballistic tests under certain conditions are always required to determine the effectiveness of the protection systems. The development of ceramic ballistic requires careful
TABLE 1: Chemical composition of the alumina used in this study (wt\%).

\begin{tabular}{lcccccc}
\hline Composition & $\mathrm{Al}_{2} \mathrm{O}_{3}$ & $\mathrm{SiO}_{2}$ & $\mathrm{CaO}$ & $\mathrm{MgO}$ & $\mathrm{Na}_{2} \mathrm{O}$ & $\mathrm{Fe}_{2} \mathrm{O}_{3}$ \\
\hline A92 & 92.0 & 2.5 & 2.3 & 2.8 & 0.1 & 0.03 \\
A96 & 96.0 & 3.1 & 0.1 & 0.6 & 0.1 & 0.04 \\
A99 & 99.7 & 0.0 & 0.0 & 0.1 & 0.1 & 0.02 \\
\hline
\end{tabular}

assessment of physical and mechanical properties of the material in order to obtain adequate performance ballistic plates to the level of protection required.

The aim of this work is to characterize alumina-based ballistic plates and to evaluate their performance in situations where high levels of kinetic energy are required.

\section{Materials and Methods}

Three alumina compositions were used in this study according to Table 1 (X-ray fluorescence spectrometry, (XRF), Philips PW 2400, The Netherlands). The mean particle sizes were determined using a laser scattering particle size analyzer (CILAS 1064L, France). Each composition was uniaxially compacted at $110 \mathrm{MPa}$ into $120 \mathrm{~mm} \times 120 \mathrm{~mm} \times 10 \mathrm{~mm}$ plates in an industrial press (Sacmi PH-300, Italy), resulting in samples presenting an apparent density of $2.44 \pm 0.04 \mathrm{~g} \cdot \mathrm{cm}^{-3}$. The specimens were then sintered at $1600 \pm 5^{\circ} \mathrm{C}$ for $6 \mathrm{~h}$ (holding time) in an industrial kiln $\left(2^{\circ} \mathrm{C} \cdot \mathrm{min}^{-1}\right.$ heating rate). After cooling down to room temperature, crystalline phases developed during heat treatment of the bodies were determined in a X-ray diffractometry (Phillips X'Pert, The Netherlands) using CuK $\alpha$ radiation, within a $2 \theta$ range of 5 to $100^{\circ}$. The theoretical densities $\left(\rho_{t}, \mathrm{~g} \cdot \mathrm{cm}^{-3}\right)$ of the sintered samples (using powdered pieces of the samples) were measured by He-pycnometry (AccuPyc 1330, Micromeritics, USA). The apparent density $\left(\rho_{\text {ap }}, \mathrm{g} \cdot \mathrm{cm}^{-3}\right)$ was determined by the Archimedes' principle by water immersion at $20^{\circ} \mathrm{C}$. The relative density $\left(\rho_{r}\right)$ was calculated from the relationship between apparent density and theoretical density according to (1), while porosity was calculated from (2):

$$
\begin{gathered}
\rho_{r}=\frac{\rho_{\text {ap }}}{\rho_{t}}, \\
\varepsilon=1-\rho_{r} .
\end{gathered}
$$

Microhardness measurements were performed with a Vickers automatic hardness tester (Shimadzu HMV, Japan) equipped with a diamond Vickers indenter. Tests were carried out with load of $1 \mathrm{~kg}$, according to Karandikar [3], for tests in ballistic ceramics. Each sample was polished for leveling surface, and submitted at least to 5 measurements. The bending strength $\left(\sigma_{f}\right)$ of the sintered samples was determined in a test machine (Model DL 2000, EMIC, Brazil), which consisted of a fourpoint test on thirty samples with dimensions of $100 \mathrm{~mm} \times$ $15 \mathrm{~mm} \times 10 \mathrm{~mm}$ at a load rate of $0.5 \mathrm{~mm} \cdot \mathrm{min}^{-1}$. Weibull distribution [11] was used to evaluate the reliability of the obtained 
TABLE 2: Standard NIJ-0108.01 test parameters for ballistic materials resistant to projectiles at different levels of ballistic protection.

\begin{tabular}{|c|c|c|c|c|c|c|}
\hline $\begin{array}{l}\text { Level of } \\
\text { ballistic } \\
\text { protection }\end{array}$ & Ammunition type & Nominal mass (g) & Barrel length $(\mathrm{cm})$ & Projectile velocity $(\mathrm{m} / \mathrm{s})$ & Kinetic energy (J) & Shots per panel \\
\hline \multirow{2}{*}{ I } & .22 LRHV Lead & 2.6 & $15-16.5$ & $320 \pm 12$ & 133.12 & \multirow{2}{*}{5} \\
\hline & .38 Special RN Lead & 10.2 & $15-16.5$ & $259 \pm 15$ & 342.12 & \\
\hline \multirow{2}{*}{ II-A } & $9 \mathrm{~mm}$ FMJ & 10.2 & $10-12$ & $381 \pm 12$ & 440.09 & \multirow{2}{*}{5} \\
\hline & .357 Mag JSP & 8.0 & $10-12$ & $332 \pm 12$ & 740 & \\
\hline \multirow{2}{*}{ II } & $9 \mathrm{~mm} \mathrm{FJM}$ & 10.2 & $15-16.5$ & $425 \pm 15$ & 512.66 & \multirow{2}{*}{5} \\
\hline & .357 Mag JSP & 8.0 & $10-12$ & $358 \pm 12$ & 921 & \\
\hline \multirow{2}{*}{ III-A } & 44 Magnum Lead SWC & 15.55 & $14-16$ & $426 \pm 15$ & 725.9 & \multirow{2}{*}{5} \\
\hline & $9 \mathrm{~mm}$ FMJ & 8.0 & $24-26$ & $426 \pm 15$ & 1406 & \\
\hline III & $\begin{array}{c}7.62 \times 51 \text { FJNB } \\
308 \text { Winchester FMJ }\end{array}$ & 9.7 & 56 & $838 \pm 15$ & 3405 & 5 \\
\hline IV & 30-06 AP & 10.8 & 56 & $868 \pm 15$ & 4068.5 & 1 \\
\hline
\end{tabular}

results and also to select the composition for the ballistic testing, according to the following for the cumulative probability of fracture:

$$
P=1-e^{\left[\left(-v / v_{0}\right) \cdot\left\{\sigma-\sigma_{u} / \sigma_{0}\right\}\right]^{m}}
$$

where $P$ is probability of fracture; $v$ is tested amount of material; $v_{0}$ is standard amount; $m$ is Weibull modulus; $\sigma$ is tensile strength of the material; $\sigma_{o}$ is parameter adjustment; $\sigma_{u}$ is strength below which the fracture probability is zero.

Considering a constant amount of specimens, (4) can be applied for a given sampling:

$$
P=1-e^{\left[-\left(\sigma-\sigma_{u}\right) / \sigma_{0}\right]^{m}},
$$

where $m, \sigma_{o}$, and $\sigma_{u}$ are known as Weibull parameters. The determination of those parameters is carried out considering firstly $\sigma_{u}=0$ and then modifying the equation into the following expression:

$$
\ln \left[\ln \left(\frac{1}{1-P}\right)\right]=m \ln \sigma-m \ln \sigma_{o}
$$

By using the linear regression method it is possible to determine the values of the parameters $m$ and $\sigma_{o}$.

Samples of sintered alumina $\left(92 \mathrm{wt} \% \mathrm{Al}_{2} \mathrm{O}_{3}, 120 \mathrm{~mm} \times\right.$ $120 \mathrm{~mm} \times 12 \mathrm{~mm}$ ) were fixed in metal plates (backing, $120 \mathrm{~mm} \times 120 \mathrm{~mm} \times 4 \mathrm{~mm}$ ) of SAE 1045 steel for the ballistic tests. A metal substrate was also designed to engage and support the specimen during the impact of the shot as shown in Figure 1.

There are two main international standards used to evaluate the performance of ballistic protection: NIJ-0101.04 and NIJ-0108.0 (National Institute of Justice) [12] and NATO (North Atlantic Treaty Organization) STANAG 4569 [13]. Tables 2 and 3 show test parameters for ballistic materials resistant to projectiles at different levels of ballistic protection, respectively for standards, NIJ-0108.01 and STANAG 4569. The ballistic testing was carried out based on the standards with the following modifications: a Mauser M1908 riffle with 7.62 AP bullets (STANAG III/NIJ IV) was used in the tests

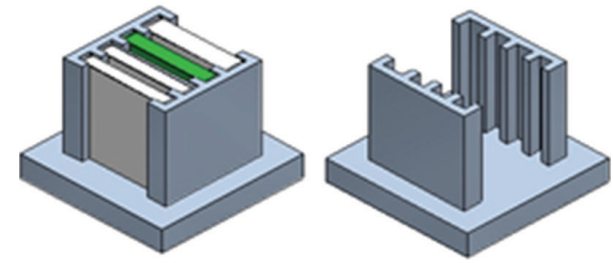

(a)

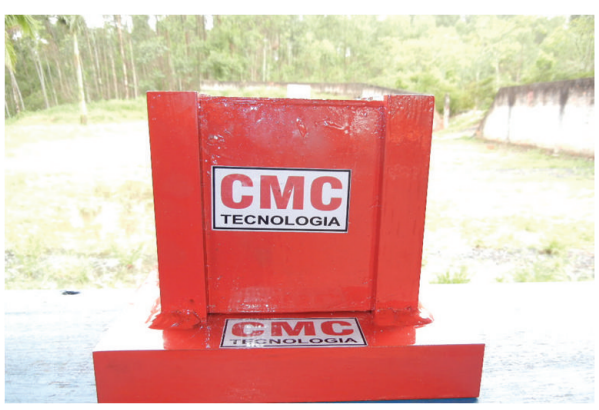

(b)

FIGURE 1: Schematic pictures of the test stand: (a) metallic substrate of the specimens; (b) specimens inserted into the metallic support.

made at $15 \mathrm{~m}$ of distance with one shot per panel. Polyurethane webs of approximately $3 \mathrm{~mm}$ thickness were placed in front of ceramic plates to retain fragments of the projectile and the ceramic released during the test. A backing plate was used as control.

\section{Results and Discussion}

Figure 2 shows the XRD patterns of the used compositions. As expected, the sintered samples were mostly constituted by $\alpha-\mathrm{Al}_{2} \mathrm{O}_{3}$ (JCPDS 10-0173). However, diffraction pattern of composition A92 showed the following minority crystalline phases: spinel $\left(\mathrm{MgAl}_{2} \mathrm{O}_{4}\right)$, wollastonite $\left(\mathrm{CaSiO}_{3}\right)$ and hibonite $\left(\mathrm{CaAl}_{12} \mathrm{O}_{19}\right)$. These phases were formed due to the sintering additives employed. 
TABLE 3: Standard STANAG 4569 test parameters for armored vehicles at different levels of ballistic protection.

\begin{tabular}{lcccc}
\hline $\begin{array}{l}\text { Level of ballistic } \\
\text { protection }\end{array}$ & Threat & Ammunition type & Test distance $(\mathrm{m})$ & Projectile velocity $( \pm 15 \mathrm{~m} / \mathrm{s})$ \\
\hline I & \multirow{2}{*}{ Rifle } & $7.62 \times 51$ NATO Ball (Ball M80) & 30 & 933 \\
& & $5.56 \times 45$ NATO SS109 & 900 \\
\hline II & Infantry rifle & $5.56 \times 45$ M193 & 30 & 695 \\
\hline III & Sniper rifle & $7.62 \times 51$ AP ( WC core $)$ & 30 & 930 \\
& & $7.62 \times 54$ R B32 API (Dragunov) & 30 & 854 \\
IV & Heavy machine gun & $14.5 \times 114$ AP/832 & 200 & 911 \\
\hline V & Automatic cannon & 25 mm APDS-TM-791 or TLB 073 & 500 & 1258 \\
\hline
\end{tabular}

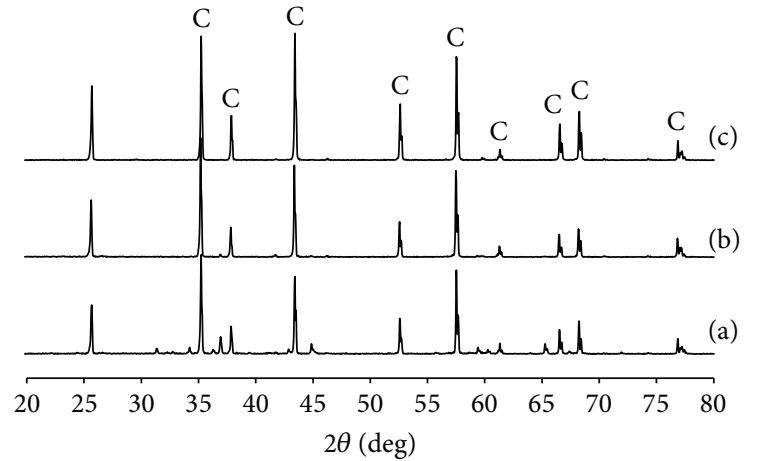

FIGURE 2: XRD patterns of the used compositions: (a) A92, (b) A96, and (c) A99. C: $\alpha-\mathrm{Al}_{2} \mathrm{O}_{3}$ (JCPDS card n. 10-0173).

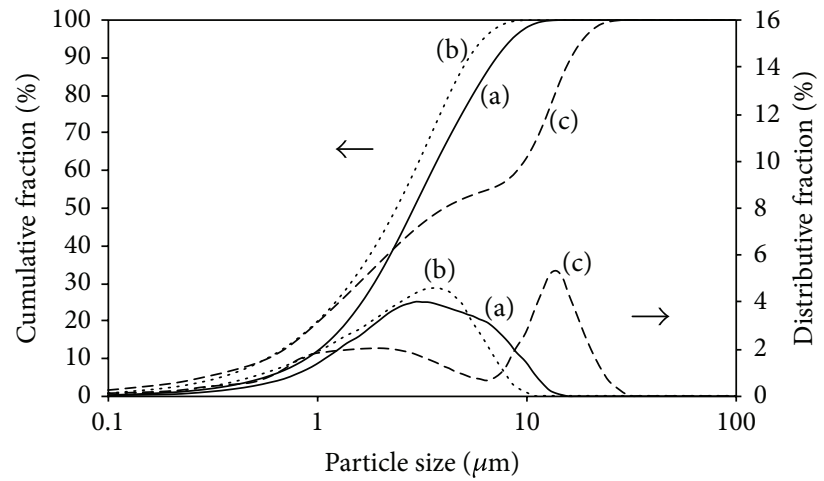

FIGURE 3: Particle size distribution of the used compositions: (a) A92, (b) A96, and (c) A99.

Figure 3 shows the particle size distribution of the used compositions. As it can be seen, those materials present a practically monomodal distribution, with mean particle size $\left(d_{50}\right)$ of $2.92,2.41$, and $4.10 \mu \mathrm{m}$, respectively, for A92, A96, and A99.

Table 4 shows values of relative density and porosity of the sintered compositions. Relative densities were found to be around $97-98 \%$. As expected, relative density decreased with increasing $\alpha-\mathrm{Al}_{2} \mathrm{O}_{3}$ contents, for the same forming pressure, sintering temperature, and holding time. Moreover, mean particle size of composition A99 was higher than the other

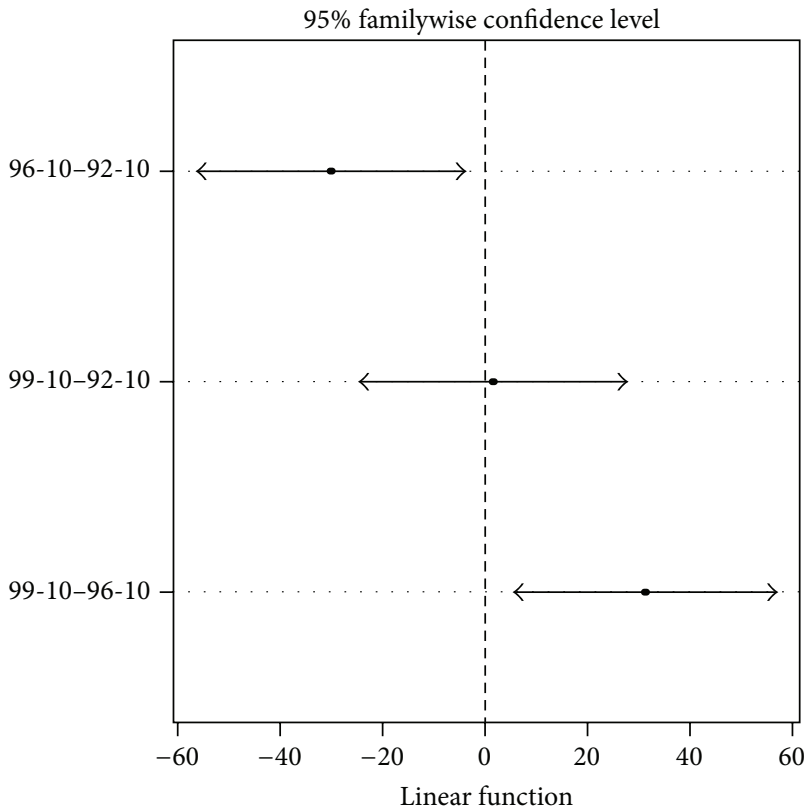

FIgURE 4: Analysis of variance (ANOVA) for a factor.

TABle 4: Apparent density, theoretical density, relative density, and porosity of the sintered compositions.

\begin{tabular}{lccc}
\hline Composition & A92 & A96 & A99 \\
\hline $\begin{array}{l}\text { Apparent density } \\
\left(\rho_{\text {ap }}, \mathrm{g} \cdot \mathrm{cm}^{-3}\right)\end{array}$ & $3.65 \pm 0.01$ & $3.70 \pm 0.01$ & $3.85 \pm 0.02$ \\
Theoretical density & $3.70 \pm 0.01$ & $3.80 \pm 0.01$ & $3.96 \pm 0.01$ \\
$\left(\rho_{t}, \mathrm{~g} \cdot \mathrm{cm}^{-3}\right)$ & 98.7 & 97.6 & 97.1 \\
Relative density $\left(\rho_{r}, \%\right)$ & 1.3 & 2.4 & 2.9 \\
Porosity $(\varepsilon, \%)$ & & & \\
\hline
\end{tabular}

ones that should have caused less accommodation of the particles and consequently more porosity compacts.

Table 5 shows values of Vickers hardness of sintered compositions. Despite of differences in porosity, the investigated compositions showed values of Vickers hardness above $14 \mathrm{GPa}$ in good agreement with values obtained by Karandikar [3] for commercial ballistic ceramics. Hardness is a very important mechanical property for ballistic application 


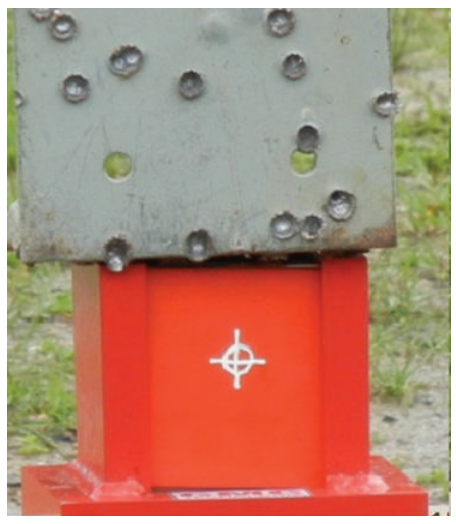

(a)

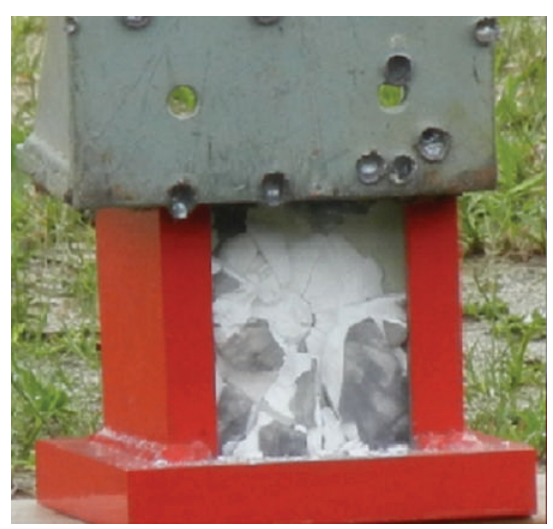

(b)

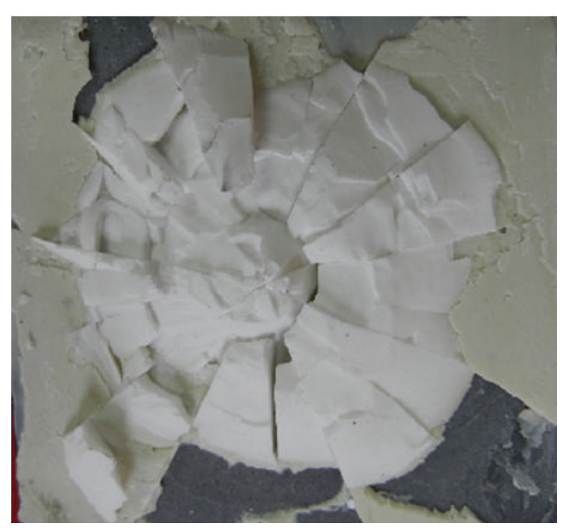

(c)

FIGURE 5: Results of the shots carried out on the ballistic plates prepared from composition A92: (a) front view before impact, (b) front view after the impact of the projectile $7.62 \times 51 \mathrm{AP}$, and (c) a detail of the local impact of the projectile on the surface of alumina after removing of the fragments.

TABLE 5: Vickers hardness of sintered compositions.

\begin{tabular}{lc}
\hline Compositions & HV (GPa) \\
\hline A92 & $14.8 \pm 0.6$ \\
A96 & $13.3 \pm 0.9$ \\
A99 & $14.8 \pm 0.7$ \\
\hline
\end{tabular}

TABLE 6: Bending strength $\left(\sigma_{f}\right)$ and Weibull modulus $(m)$ for the tested compositions.

\begin{tabular}{lccc}
\hline Composition & A92 & A96 & A99 \\
\hline$\sigma_{f}(\mathrm{MPa})$ & $221 \pm 40$ & $195 \pm 40$ & $227 \pm 20$ \\
$\sigma_{f 50}(\mathrm{MPa})$ & 225 & 201 & 231 \\
$m$ & 6.4 & 4.8 & 8.0 \\
\hline
\end{tabular}

since it is expected the rupture of the projectile by the ballistic plate.

Table 6 shows values of bending strength and Weibull modulus for the studied compositions. All compositions presented similar values of bending strength considering the standard deviations presented. Nevertheless, compositions A92 and A99 showed practically the same average values of bending strength, which are higher than the ones for composition A96. This can be statistically confirmed with a $95 \%$ of confidence level by the analysis of variance and hypothesis test, as shown in Tables 7 and 8, and Figure 4.

Moreover, composition A96 showed a very lower value of $m$ in comparison with compositions A92 and A99 for a technical application. In fact, technical ceramics must show values of $m$ ranging from 5 to 10 according to Kanno [14]. In this sense and considering the value of $\sigma$, composition A96 could not be used for ballistic tests. On the other hand, compositions A92 and A99 showed suitable values of $m$ for technical application and there is no statistical evidence of significant difference between them, as shown by their linear function. However, because of its lower porosity, composition A92 was selected for ballistic tests.
TABLE 7: Results of statistical hypothesis test.

\begin{tabular}{lcccc}
\hline Linear hypotheses & Estimate & SD Error & $T$ value & $\operatorname{Pr}(>|t|)$ \\
\hline 96-10-92-10 & 29.676 & 10.973 & -2.704 & 0.0223 \\
99-10-92-10 & 1.647 & 10.973 & 0.150 & 0.9877 \\
99-10-96-10 & 31.323 & 10.681 & 2.933 & 0.0120 \\
\hline
\end{tabular}

TABLE 8: Results of the analysis of variance.

\begin{tabular}{lccc}
\hline Linear hypotheses & Estimate & Lower & Upper \\
\hline 96-10-92-10 & -29.6763 & -55.8574 & -3.4952 \\
$99-10-92-10$ & 1.6465 & -24.5346 & 27.8276 \\
$99-10-96-10$ & 31.3229 & 5.8401 & 56.8056 \\
\hline
\end{tabular}

Figures 5 and 6 show the results of the shots on the ballistic plates prepared from composition A92. In fact, a high amount of energy was absorbed by the alumina plate causing its fracture. Nevertheless, its hardness caused the breaking of the projectile into small fragments. Fragments did not penetrate or cause deformation in none of the backing (metallic plates) of the five plates tested. The velocity of the projectile in the impact was estimated to be $\sim 865 \mathrm{~m} \cdot \mathrm{s}^{-1}$, while the kinetic energy should be above $4000 \mathrm{~J}$. In this way, all the tested plates were approved in the ballistic tests (Level IV of Standard NIJ-0108.01). Those results are in very good agreement with those obtained by Karandikar [3] (alumina, $10 \mathrm{~mm}$ thickness) and above to those obtained by Couto [7] (level III, alumina/zirconia, $11.3 \mathrm{~mm}$ thickness).

\section{Conclusion}

Three compositions of commercial alumina containing 92, 96, and $99.7 \mathrm{wt} \% \mathrm{Al} 2 \mathrm{O} 3$, named compositions A92, A96, and A99, respectively, were investigated in this work to be used as ballistic ceramics. Compositions were characterized by Vickers hardness measurements and four point flexural bending strength. The reliability of the obtained results was evaluated 


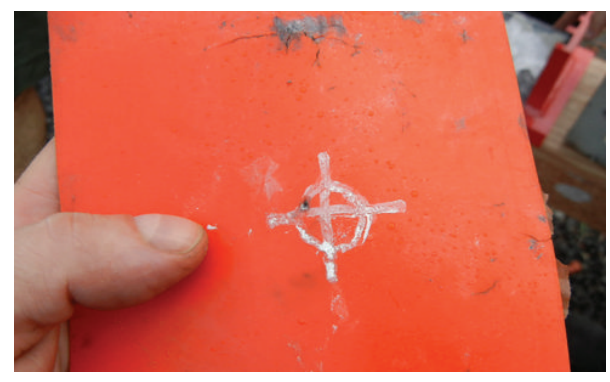

FIGURE 6: View of the hole caused by the shot over the plate of polyurethane.

by Weibull statistics. According to the obtained results, one composition was selected for the ballistic testing. Compositions A92 and A99 showed comparable results with each other and higher Vickers hardness and bending strength than composition A96; however, composition A92 was selected for ballistic tests because of its lower porosity. Alumina plates (12 $\mathrm{mm}$ thickness) were submitted to a procedure based on the Standard NIJ-0108.01 (Level IV, $865 \mathrm{~m} \cdot \mathrm{s}^{-1}$, more than $4000 \mathrm{~J}$ ). Fragments did not penetrate or cause deformation in none of the backing (metallic plates) of the five plates tested. All the tested plates were approved in the ballistic tests.

\section{Conflict of Interests}

The authors declare that there is no conflict of interests regarding the publication of this paper.

\section{Acknowledgment}

The authors are grateful to Coordenação de Aperfeiçoamento de Pessoal de Nível Superior (CAPES/Brazil) for funding this work.

\section{References}

[1] S. Yadav and G. Ravichandran, "Penetration resistance of laminated ceramic/polymer structures," International Journal of Impact Engineering, vol. 28, no. 5, pp. 557-574, 2003.

[2] C. Xavier and C. R. C. Costa, "Study on mechanical behavior of alumina plates under ballistic impact," Cerâmica, vol. 30, no. 175, pp. 161-168, 1984.

[3] P. G. Karandikar, "A review of ceramics for armor applications," in Advances in Ceramic Armor IV, vol. 29, pp. 163-175, The American Ceramic Society, 2009.

[4] R. E. Tressler, "An assessment of low cost manufacturing technology for advanced structural ceramics and its impact on ceramic armor," Ceramic Transactions, vol. 134, pp. 451-462, 2002.

[5] R. Stevens and P. A. Evans, "Transformation toughening by polycrystalline zirconia," Transactions and Journal of the British Ceramic Society, vol. 83, no. 1, pp. 18-31, 1984.

[6] R. B. Heimann, Classic and Advanced Ceramics: From Fundamentals to Applications, Wiley-VCH, New York, NY, USA, 2010.

[7] C. A. O. Couto, Estudo de blindagem para proteção contra impactos de micrometeoróides em satélites artificiais [Mestrado em Engenharia e Tecnologia Espaciais/Materiais e Sensores],
Instituto Nacional de Pesquisas Espaciais, São José dos Campos, Brazil, 20112011.

[8] "Matweb Material Property Data, Alumina, alpha $\mathrm{Al}_{2} \mathrm{O}_{3}, 99$. 5\%," http://www.matweb.com/search/PropertySearch.aspx.

[9] L. Neckel, Modelamento e simulação de impacto balístico em sistema cerâmica-metal [Mestrado em Ciência e Engenharia de Materiais], Programa de Pós-Graduação em Ciência e Engenharia de Materiais, Universidade Federal de Santa Catarina, Florianópolis, Brazil, 20122012.

[10] M. L. Wilkins, "Mechanics of penetration and perforation," International Journal of Engineering Science, vol. 16, no. 11, pp. 793-807, 1978.

[11] W. Weibull, "A statistical distribution function of wide applicability," Journal of Applied Mechanics, vol. 18, pp. 293-297, 1951.

[12] National Institute of Justice Standard, "Ballistic resistance of body armor," Tech. Rep. NIJ-0101.06, 2008.

[13] North Atlantic Treaty Organization, "Standards for Ballistic protection for light armoured vehicles," Stanag 4569, 2008.

[14] W. M. Kanno, Propriedades Mecânicas do Gesso de Alto Desempenho [Doutor em Ciência e Engenharia de Materiais], Área de Concentração, Desenvolvimento, Caracterização e Aplicação de Materiais, Universidade de São Paulo, São Carlos, Brazil, 2009 2009 . 

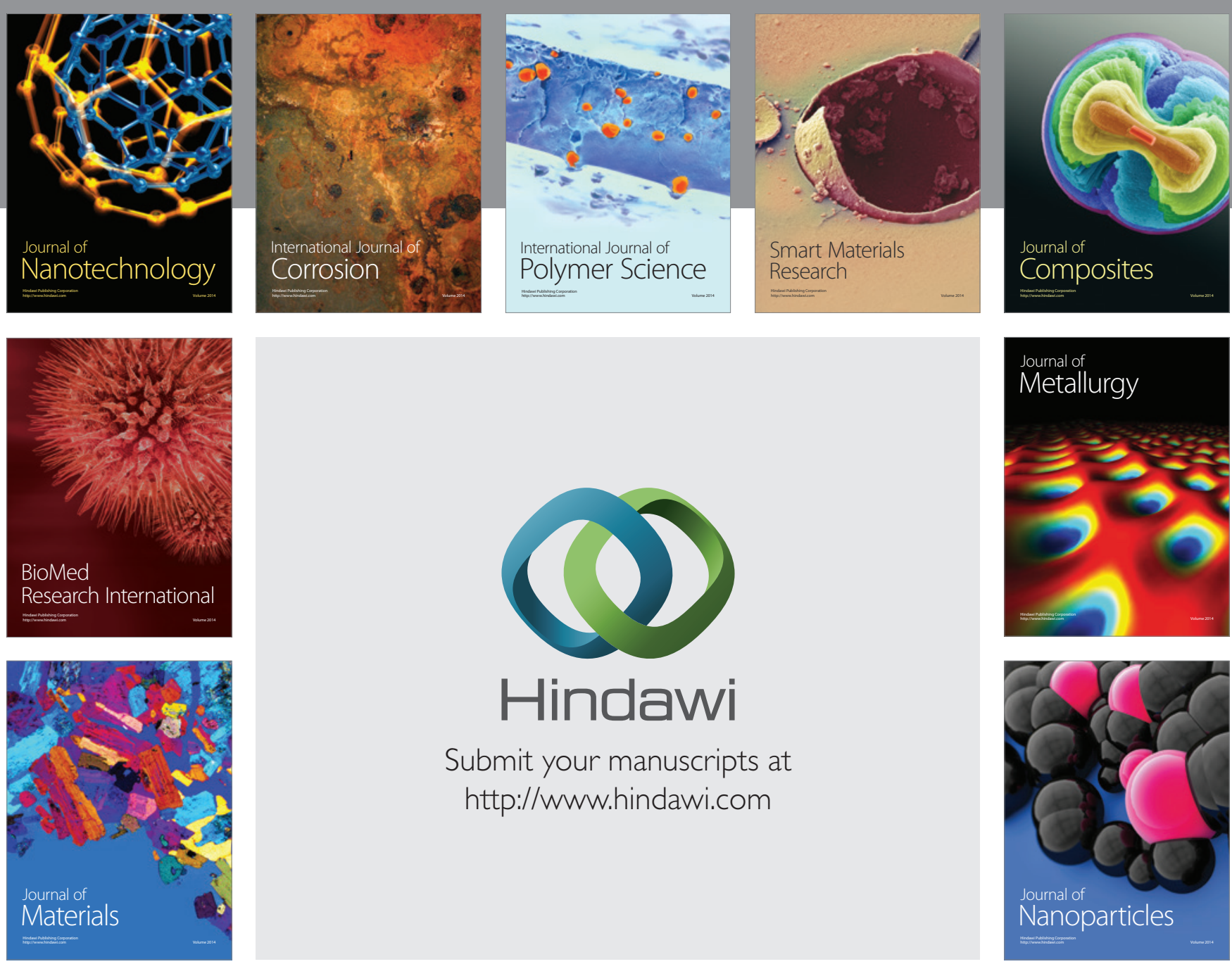

Submit your manuscripts at http://www.hindawi.com
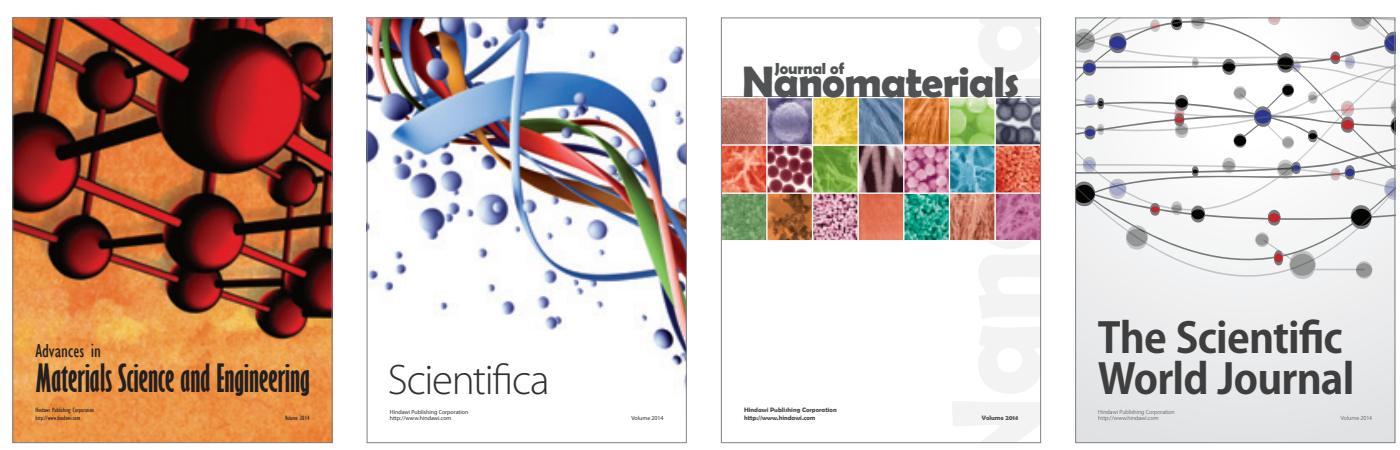

\section{The Scientific World Journal}
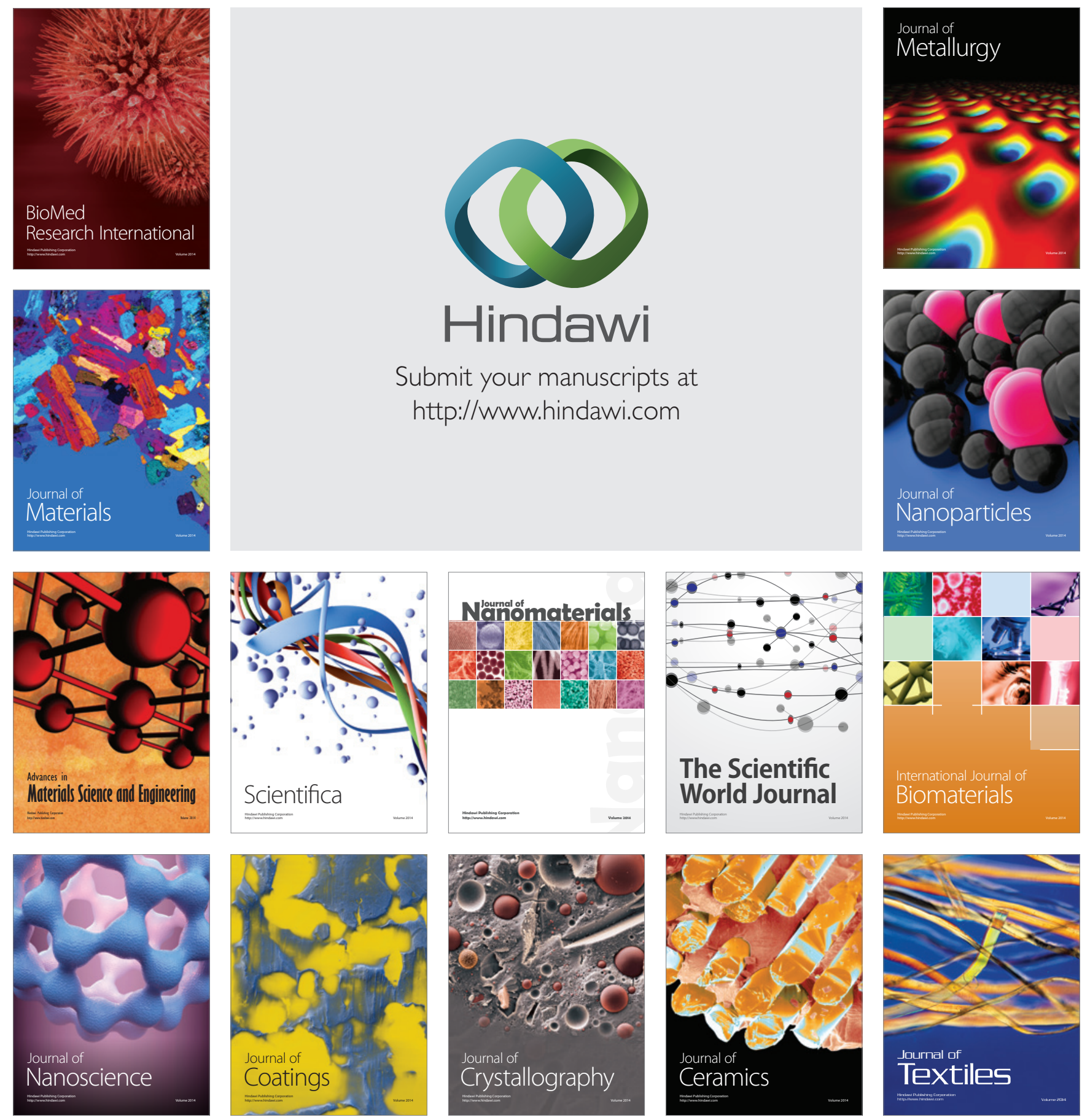